\title{
Application of SQQ-Based Flipped Classroom Model on Students' Achievement and Engagement in ICT Course
}

\author{
Mona Masood $^{1 *}$ (D), Kamaludeen Samaila ${ }^{2}$ (), Kien T. Chau ${ }^{1}$ (])
}

${ }^{1}$ Centre for Instructional Technology and Multimedia, Universiti Sains Malaysia, Penang, MALAYSIA

${ }^{2}$ Kebbi State University of Science and Technology, Aliero, Kebbi State, NIGERIA

*Corresponding Author: msmona@usm.my

Citation: Masood, M., Samaila, K., \& Chau, K. T. (2022). Application of SQQ-Based Flipped Classroom Model on Students' Achievement and Engagement in ICT Course. Mediterranean Journal of Social \& Behavioral Research, 6(1), 21-26. https://doi.org/10.30935/mjosbr/11527

\begin{abstract}
There is an agitation from teacher educators and experts that the traditional lecture-based method is no longer appropriate in teaching Information and Communication Technology (ICT) courses. Though, the government through its policies and reforms introduced ICT courses to schools and colleges to boost students' ICT knowledge and skills for economic and national development. Studies from across all parts of the world show that using the traditional lecture-based method in teaching the ICT courses had affected students' academic achievement and engagement. Scholars suggested using technologies and student-centered learning approaches to improve students' achievement and engagement, particularly in the ICT courses. Flipped classroom model is one of the teaching and learning pedagogies that can overcome the limitations of the traditional lecture-based method. Few studies have investigated the effect of flipping classroom model for the students taking ICT courses. Hence, this paper presents a modified flipped classroom model to improve students' achievement and learning engagement. The modified flipped classroom model comprises of social constructivist learning theory, bloom taxonomy, cooperative learning model, and study-quiz-question (SQQ) learning strategy.
\end{abstract}

Keywords: ICT knowledge, flipped classroom model, cooperative learning model, bloom taxonomy, social constructivism, SQQ

Received: 8 Oct. $2021 \bullet$ Accepted: 29 Nov. 2021

\section{INTRODUCTION}

For more than decades, the traditional lecture-based method has been used in most universities, colleges, and schools to impart knowledge and experiences. These institutions are being challenged by the modern days' needs to improve student's ICT knowledge and learning engagement. To accomplish this goal, Nigerian government introduced and made computer and ICT courses mandatory at various levels of education to expose students to several ICT tools and applications. For this study, ICT knowledge refers to the student's ability to use the Internet, computer database, word processing, Microsoft Excel, and presentation softwires for creating, managing, and storing information. ICT knowledge reduces digital illiteracy within society (Kaarakainen et al., 2018). It allows students to access learning materials online and collaborate with their colleagues, teachers, and experts to attain a certain level of knowledge (Kaware \& Sunil, 2015). In Africa, especially Nigeria, most of the students found to have limited ICT knowledge due to some factors such as inadequate resources, financial issues, and lack of appropriate teaching pedagogies (Omotayo et al., 2020). The choice of teaching method had always influenced the students' engagement and learning outcomes (Roorda et al., 2011).
Now a day, teachers are being looking for the appropriate methods to fully engage the students with content in and outside the classroom (Stronge, 2018). Engagement is a student's active involvement in a learning activity. It is a critical element for boosting students' academic progress and promoting active learning (O'Donnell et al., 2011). Students' engagement represents the range of actions they take to progress from not knowing, not understanding, not having skill, and not achieving to knowing, understanding, having skill, and achieving (Reeve, 2013).

Student's engagement during pre-class activities and in-class activities plays a significant role in achieving high learning outcomes in the flipped classroom model. Though engagement is one of the critical factors that enhance learning achievement (Jang et al., 2012). Studies reported that the level of student's engagement during the ICT/computer course lectures in Nigerian universities was low (Samuel et al., 2019; Zakana \& Esther, 2019). Study reported that using the traditional lecture-based method was among the causes of students' low engagement in Nigeria (Adedoja, 2016).

Under this circumstance, the teaching of ICT courses needs to change from a traditional-lecture-based approach to a technology based-approach and student-centred learning approach. One such 
approach is flipped classroom teaching approach. This article describes the effect of the modified flipped classroom model on students' achievement and engagement. The modified flipped classroom is supported by the cooperative learning model, constructivist theory, bloom's taxonomy, and study-quiz-question (SQQ) learning strategy.

\section{BACKGROUND OF THE STUDY}

ICT knowledge is an essential requirement for every student to work independently, access information, and collaborate with experts to ascertain some levels of education (Kaarakainen et al., 2018). At the university level, the ICT topics include computer database, Internet skills, Microsoft offices, information security, information networking, image processing, and social networking. Disappointingly, in Nigeria these contents are all taught using the traditional lecture-based method. Hence, may be the reason for the students' limited ICT knowledge and less engagement. Some ICT topics require a technology-based teaching approach and a student-centred learning approach (Wen et al., 2017). Modern teaching models need to be employed to achieve optimal learning outcomes and maximum engagement (Willingham et al., 2015). Research shows that majority of the teachers are rigid to transform their teaching strategies from traditional lecture-based methods to modern teaching methods (Alrahlah, 2016). The modern teaching methods are those that are central to successful learning. These include but not limited to blended learning, flipped, or inverted classroom models, problem-based learning, project-based learning, discovery method, and cooperative learning.

Flipped or inverted classroom model is one of the modern teaching and learning models that combines student-centred learning approach with synchronous e-learning, asynchronous e-learning, or a mixture. Interestingly, in the flipped or inverted classroom, the instructors guide and facilitate the learning process, while the students are responsible for their learning activities and must oversee their own learning pace (Lai $\&$ Hwang, 2016). The flipped classroom model utilizes pre-class time (at home) and in-class time (Bishop \& Verleger, 2013; Missildine et al., 2013). The model possesses the ability to allow students to manage their learning activities, decide when, where, and how to learn when given learning materials (Xu \& Shi, 2018). Though flipped classroom model offered many positive learning outcomes, researchers argued that more innovations need to be integrated into the model to overcome its limitations and challenges (Lin et al., 2019).

\section{Flipped Classroom Model}

Today, the concept of flipped classroom model has been adapted and implemented in different fields of study (science, social science, management, humanities, engineering, and technologies) and at universities, colleges, and schools levels (Hao, 2016). Flipped classroom model is a popular teaching and learning strategy in which the students are exposed to learning materials before the class hour, while in the classroom they solve complex problems, discuss, present, and deal with everyday life situations (Stone, 2012). In other dimension, a flipped classroom is an instructional strategy that allows interactive groupbased learning activities in the classroom and direct computer-based individual instruction outside the classroom (Bishop \& Verleger, 2013). It was reported that flipped classroom model enhanced students' learning achievement (Long et al., 2018; Missildine et al., 2013; Zainuddin et al., 2019) and engagement (Jamaludin \& Zuraidah, 2014; Stone, 2012). The model allows students to access lecture materials in advance before class time and offers opportunities for in-depth discussion and hands-on practical during class time.

Despite the advantages of the flipped classroom model, many studies reported limitations and challenges associating with the model. For instance, students' disengagement (Lai \& Hwang, 2016; Zainuddin et al., 2019), low self-regulated learning behaviours (Sun et al., 2017), and inadequate time to redesigned lesson plans and courses (Schlairet et al., 2014). To date, only few studies (e.g., Heo \& Chun, 2016; Lai \& Hwang, 2016) have conducted studies toward solving these challenges. Therefore, this study advocates a modified flipped classroom model to overcome the limitations and challenges of a conventional flipped classroom model and enhance students' achievement and engagement.

\section{Modified Flipped Classroom Model}

Due to the limitations and challenges confronting the conventional flipped classroom model, a modified flipped classroom model was developed. The challenges include a lack of a designated strategy for students to complete their learning activities during pre-class activities (Jump, 2013). Students cannot interact with their teachers and peer during pre-class activities (Lo et al., 2018). The conventional flipped classroom model relies heavenly on the completion of pre-class learning activities; inadequate preparation may reduce the effectiveness of the flipped classroom model (Samaila et al., 2021). Scholars suggested that sophisticated innovations need to be used to overcome the challenges (Hsia et al., 2019; Lin et al., 2019; Samaila et al., 2021). In the same vein, learning theories should be employed to guide the in-class learning activities (Kim et al., 2014). The modified flipped classroom consists of three main sections (pre-class, in-class, and post-class).

\section{Pre-class section}

In the conventional flipped model, students reported having challenges during pre-class learning activities such as disengagement, unable to watch instructional videos, and feeling reluctant to complete their tasks. In the modified flipped classroom model, the study-quizquestion (SQQ) strategy is developed to engage the students during preclass activities. The SQQ strategy is a platform developed using Google Form; it allows students to submit their quizzes and ask questions after watching the given instructional videos. The strategy has three activities that every student can do before the class hour. The three activities explain in the following steps:

Step 1-Study (S): In this step, the instructors upload the instructional videos and other learning materials on the learning management system (LMS). Students watch the instructional videos and study the learning materials before the class hour. For example, in an ICT class, an instructor may upload the instructional video of Internet skills on the LMS. The students are expected to watch the video before class time.

Step 2-Quiz (Q): The instructor should create questions for the quiz from the video and learning materials. Students should access the Google Form quiz link through the LMS, thereby completing their preclass activities.

Step 3-Questions (Q): Students ask questions from the instructional video and learning materials against the next class. This engages the students and helps the instructor to assess where students need more explanation.

The SQQ strategy has similar functions and characteristics with watch-summarize-question (WSQ). While instructors used the WSQ 
strategy to collect students' feedback manually (Hsia et al., 2019), those who used the SQQ strategy collect students' feedback using the technology (Google Form). If this strategy is carefully used, students' engagement during pre-class activities can be enhanced.

\section{In-class section}

For the in-class learning activities, flexible learning theories are needed to attain optimal learning outcomes through peer-to-peer discussion. Social interaction between teacher-student or studentstudent plays a significant role in constructing new ideas and knowledge. Therefore, cooperative learning (think-pair-share - TPS) and social constructivist learning were integrated into the modified flipped classroom to reinforce the in-class activities. The TPS model has three different activities that ought to be done in the classroom. The activities are as follow:

Think (T): For the in-class activities, the first thirty minutes are for the students to work individually. For instance, each student should use a computer to create PowerPoint presentation slides.

Pair (P): At this stage, the instructor divides the students into groups of four based on homogeneous and heterogeneous. Each group should collaborate, work together, and come up with PowerPoint presentation slide with background, pictures, videos, animation, and transition.

Share (S): At this stage, students share their experiences in the classroom, present how they made their slides, how they inserted the videos, pictures, and other features in the slides.

\section{Post-class section}

There are few activities for the students in the post-class. Instructors should facilitate and arrange for the students to make group/individual presentations where necessary. The instructor should evaluate the lesson by asking questions, encourage students to more questions.

\section{Application of Learning Theories in Modified Flipped Classroom Model}

Scholars use learning theories to provide a basis to comprehend how students learn; explain how students receive, process, and retain information during flipped learning. This section discusses the application of cooperative learning theory, bloom's taxonomy, social constructivist learning theory, and study-quiz-question (SQQ) strategy in the modified flipped classroom model.

\section{Cooperative Learning Theory in Modified Flipped Classroom Model}

Cooperative learning is a teaching and learning approach that allows learners to work together to achieve a common goal (Johnson \& Johnson, 2002). Cooperative learning theory guides the student to think individually towards solving a task, pair with colleagues to solve a task, share thoughts with the colleagues and teachers on how to solve a problem. Empirical studies indicated that students who had used cooperative learning theory were more committed to pursuing their goals (Gillies, 2016; Van Ryzin \& Roseth, 2019). However, few studies integrate cooperative learning theory (TPS) into the flipped classroom model to enhance student's learning achievement and engagement (Jian, 2019; Manoj et al., 2019). Therefore, this study explains the impact of integrating the TPS approach into the modified flipped classroom model.
The reason for integrating the TPS approach into the modified flipped classroom model is to strengthen in-class learning. In the modified flipped classroom model, the role of the TPS is to define the role of the instructor and students. The instructor's role is to organize the class, facilitate learning, guide the students, and divide them based on homogeneous and heterogeneous. The role of students is to carry out the task based on the TPS strategy and lead the process of learning.

Bloom's Taxonomy in Modified Flipped Classroom Model

Bloom's taxonomy has been used as an academic framework that assists the teacher to categorize what learners are expected to learn during the learning process (Sarawagi, 2013). Modified bloom's taxonomy has six main categories in the cognitive domain. The categories were remembering, understanding, applying, analysing, evaluating, and creating. Though studies integrated bloom's taxonomy into flipped classroom model in developed countries (Sarawagi, 2013; Zainuddin et al., 2018), few or no studies were conducted in West African countries. Thus, this study integrates bloom's taxonomy in the modified flipped classroom model to describe and categorize what students should do during pre-class, in-class, and post-class sections.

Bloom's taxonomy classified the learning process into lower levels (remembering and understanding) and higher levels (applying, analysing, evaluating, and creating) (Sarawagi, 2013). Zainuddin et al. (2018) argued that taxonomy and flipped classroom model have similar ideology as both agreed that lower levels of learning should occur before class hour while higher levels of learning take place in the classroom under the supervision of the instructors. In addition, both agreed that transmission of knowledge occurs before going to the class and assimilation of knowledge which requires critical thinking happens inside the classroom.

For example, in an ICT class, the topic of "Internet skills" was to be taught using a modified flipped classroom model and bloom's taxonomy. In the pre-class section, the students should be guided to have basic knowledge (e.g., the meaning of the Internet, uses of the Internet, and Internet facilities) and let the students understand and remember the learning contents (lower level of bloom's taxonomy). For in-side class and post-class activities, the students should be exposed to higher levels of learning such as applying, analysing, evaluating, and creating (e.g., downloading a picture from a website, editing a PDF file online, and sending an email)

\section{Social Constructivist Learning Theory in Modified Flipped Classroom Model}

The social constructivist learning theory believes that students are the subject of cognition and the core of teaching. Compared with the conventional teaching method, the social constructivist teaching method encourages students to participate in the learning process and manage their learning pace independently. The theory values the opinions of the students and recognizing students as the active constructors of knowledge meaning. On the other hand, the theory argues that teachers should only facilitate and guide the students to construct meaningful knowledge and are not allowed to disseminate information or impart knowledge directly to students (Eppard \& Rochdi, 2017). Unlike in the conventional method of teaching where a teacher is the source of information and knowledge, in the social constructivist teaching method, the teacher creates a conducive learning environment for a student to expand their learning through social interaction and cooperative learning (Alzahrani, 2016). 
Likewise, in a flipped classroom, students are the centre of teaching and active constructors of knowledge. Before going to the class, students access relevant learning materials through LMS or YouTube to have their autonomous construction of knowledge. Both flipped classroom model and social constructivist learning theory believed that students are the constructors of knowledge, the leader, and the controller of their learning process.

The reason for integrating social constructivist theory into the modified flipped classroom model is to back in-class activities with theoretical justification. To help instructors understand their roles as facilitators, planners, and organizers of the learning process. To spell out the role of the students as active participants in the learning process.

\section{Application of SQQ Strategy in Modified Flipped Classroom Model}

The SQQ strategy is one of the strategies that assist students to complete their learning activities in the pre-class section of the flipped learning model. The learning activities in the SQQ strategy include studying learning materials, taking quizzes, and asking questions in the pre-class stage. These activities promote students' engagement and ensure students acquire basic knowledge before the class hour. Furthermore, the SQQ strategy supports the teachers to understand the level of students' understanding before class time. The completion of pre-class activities in the flipped classroom is the key to the successful implementation of in-class activities in flipped learning. Therefore, the SQQ strategy was introduced in the modified flipped classroom model to support pre-class activities and enhance students' engagement. If there is a high level of student's engagement, the student's learning achievement will be positive. In summary, the SQQ strategy is directly influenced students' engagement by supporting students with a platform to complete their learning activities. It is believed that students who have high level of engagement will have better learning achievement (O’Donnell et al., 2011).

\section{PROPOSED METHODOLOGY}

A quasi-experimental study is mostly used to examine the effectiveness of a specific intervention on student's academic achievement. For example, a researcher wanted to examine the effect of a modified flipped classroom model on students' achievement and engagement in ICT course. The students can be divided into two groups (A and B). Group A should use a modified flipped classroom model, and group B should use the conventional flipped classroom model or traditional teaching method. The student's achievement is measured using the ICT achievement test and student engagement is measured using an engagement questionnaire. A Pre-test can be administered before the intervention and a post-test after the intervention. Analysis of variance (ANOVA) can be used to analyse the data where there are two groups or three groups with two or more dependent variables. In a situation where pre-test serves as covariant, the analysis of covariance (ANCOVA) can be used to analyse the data.

The following is the summary of how the flow of modified flipped classroom work:

1. Initially, before the class time, instructors are expected to create and upload instructional videos and other learning materials on the LMS of a particular ICT course. Generate SQQ activities using Google Form. Students are to log in to the LMS, access and study the materials (at home). After that, complete the SQQ activities. These are the pre-class activities of both instructors and students in the modified flipped classroom model.

2. After completing the pre-class activities, the next step is in-class activities. The instructors should conduct a mini lecture to clarify issues and misconceptions that may arise. The instructor should share the students into groups of four and guide them to learn based on the TPS and social constructivist learning approach. The construction of knowledge (applying, analysing, evaluating, and creating) occurs in this stage.

3. After students completed the in-class activities, the instructor should encourage the students to share their experience with the class members and guide them to make individual/group presentations where necessary. In the end, new instructional videos and SQQ activities' links should be uploaded to the LMS.

\section{CONCLUSIONS}

The flipped classroom model has been widely accepted and applied across many disciplines. Compared with the traditional lecture-based method, the conventional flipped classroom teaching method encourages student-centered learning. Despite the positive impact of the conventional flipped classroom model, some of its challenges need to be tackled. The challenges are the lack of a designated strategy for students to complete their learning activities while at home, students' disengagement, and limited integration of learning theories to support in-class activities. The issue of a designated strategy to guide students during out-of-class activity has been overcome by developing the SQQ strategy. This strategy serves as a guide and platform that support students to complete their activities. Teachers and lecturers can adapt the strategy to strengthen their pre-class section while implementing flipped classroom model. This study argues that the integration of the SQQ strategy in the pre-class stage reduces the level of students' disengagement in flipped learning. Cooperative learning theory, bloom taxonomy, and social constructivist learning theory can be integrated to support in-class activities. Flipped educators are advised to adopt at least two of the theory to strengthen their in-class learning activities

Author contributions: All authors were involved in concept, design, collection of data, interpretation, writing, and critically revising the article. All authors approve final version of the article.

Funding: The authors received no financial support for the research and/or authorship of this article.

Declaration of interest: Authors declare no competing interest.

Data availability: Data generated or analysed during this study are available from the authors on request.

\section{REFERENCES}

Adedoja, G. (2016). Pre-service teachers' challenges and attitude toward the flipped classroom. African Educational Research Journal, 4(1), 1318 .

Alrahlah, A. (2016). How effective the problem-based learning (PBL) in dental education. A critical review. Saudi Dental Journal, 28(4), 155161. https://doi.org/10.1016/j.sdentj.2016.08.003 
Alzahrani, I. (2016). The role of the constructivist learning theory and collaborative learning environment on Wiki classroom and the relationship between them. International Journal of Educational and Pedagogical Sciences, 10(3), 891-894.

Bishop, J., \& Verleger, M. (2013). Testing the flipped classroom with model-eliciting activities and video lectures in a mid-level undergraduate engineering course. In 2013 IEEE Frontiers in Education Conference (pp. 161-163). https://doi.org/10.1109/ FIE.2013.6684807

Eppard, J., \& Rochdi, A. (2017). A framework for flipped learning. In Proceedings of the 13th International Conference on Mobile Learning (pp. 33-40).

Gillies, R. M. (2016). Cooperative learning: Review of research and practice. Australian Journal of Teacher Education, 41(3), 39-54. https://doi.org/10.14221/ajte.2016v41n3.3

Hao, Y. (2016). Exploring undergraduates' perspectives and flipped learning readiness in their flipped classrooms. Computers in Human Behavior, 59, 82-92. https://doi.org/10.1016/j.chb.2016.01.032

Heo, H. J., \& Chun, B. A. (2016). A study on the effects of mobile-based LMS on flipped learning: Focused on the affective pathway in preservice teacher education. International Journal of Software Engineering and Its Applications, 10(12), 473-484. https://doi.org/ 10.14257/ijseia.2016.10.12.39

Hsia, L.-H., Hwang, G.-J., \& Lin, C.-J. (2019). A WSQ-based flipped learning approach to improving students' dance performance through reflection and effort promotion. Interactive Learning Environments, 1-16. https://doi.org/10.1080/10494820.2019. 1651744

Jamaludin, R., \& Zuraidah, M. O. (2014). The use of a flipped classroom to enhance engagement and promote active learning. Journal of Education and Practice, 5(2), 124-131.

Jang, H., Kim, E. J., \& Reeve, J. (2012). Longitudinal test of selfdetermination theory's motivation mediation model in a naturally occurring classroom context. Journal of Educational Psychology, 104(4), 1175-1188. https://doi.org/10.1037/a0028089

Jian, Q. (2019). Effects of digital flipped classroom teaching method integrated cooperative learning model on learning motivation and outcome. Electronic Library, 37(5), 842-859. https://doi.org/ 10.1108/EL-02-2019-0024

Johnson, D. W., \& Johnson, R. T. (2002). Cooperative learning methods: A meta-analysis. Journal of Research in Education, 12(1), 524.

Jump, L. (2013). 'Flipping the classroom': A theoretical and practical exploration. Compass: Journal of Learning and Teaching, 4(8). https://doi.org/10.21100/compass.v4i8.99

Kaarakainen, M. T., Kivinen, O., \& Vainio, T. (2018). Performancebased testing for ICT skills assessing: a case study of students and teachers' ICT skills in Finnish schools. Universal Access in the Information Society, 17(2), 349-360. https://doi.org/10.1007/ s10209-017-0553-9

Kaware, S. S., \& Sunil, K. S. (2015). ICT application in education: An overview. International Journal of Multidisciplinary Approach and Studies, 2(1), 25-32.
Kim, S. H., Park, N. H., \& Joo, K. H. (2014). Effects of flipped classroom based on smart learning on self-directed and collaborative learning. International Journal of Control and Automation, 7(12), 69-80. https://doi.org/10.14257/ijca.2014.7.12.07

Lai, \& Hwang, G. J. (2016). A self-regulated flipped classroom approach to improving students' learning performance in a mathematics course. Computers and Education, 100, 126-140. https://doi.org/ 10.1016/j.compedu.2016.05.006

Lin, H. C., Hwang, G. J., \& Hsu, Y. D. (2019). Effects of ASQ-based flipped learning on nurse practitioner learners' nursing skills, learning achievement and learning perceptions. Computers and Education, 139, 207-221. https://doi.org/10.1016/j.compedu.2019. 05.014

Lo, C. K., Lie, C. W., \& Hew, K. F. (2018). Applying "first principles of instruction" as a design theory of the flipped classroom: Findings from a collective study of four secondary school subjects. Computers and Education, 118, 150-165. https://doi.org/10.1016/j.compedu. 2017.12.003

Long, T., Cummins, J., \& Waugh, M. (2018). Investigating the factors that influence higher education instructors' decisions to adopt a flipped classroom instructional model. British Journal of Educational Technology, 50(3), 1-12. https://doi.org/10.1111/bjet.12703

Manoj, K., Renumol, V., \& Murthy, S. (2019). Flipped classroom strategy to help underachievers in Java programming. In 2018 International Conference on Learning and Teaching in Computing and Engineering (pp. 44-49). https://doi.org/10.1109/latice.2018.000-7

Missildine, K., Fountain, R., Summers, L., \& Gosselin, K. (2013). Flipping the classroom to improve student performance and satisfaction. Journal of Nursing Education, 52(10), 597-599. https://doi.org/10.3928/01484834-20130919-03

O’Donnell, A. M., Reeve, J., \& Smith, J. K. (2011). Educational psychology: Reflection for action. Wiley.

Omotayo, O. O., Emiloju, A. O., Olawale, K., \& Nathaniel, S. (2020). Assessment of teachers' pedagogical knowledge on the utilization of information and communication technology in Kwara State, Nigeria. International Journal of Education and Development Using Information and Commnunication Technology, 16(1), 62-71.

Reeve, J. (2013). How students create motivationally supportive learning environments for themselves: The concept of agentic engagement. Journal of Educational Psychology, 105(3), 579-595. https://doi.org/10.1037/a0032690

Roorda, D. L., Koomen, H. M. Y., Spilt, J. L., \& Oort, F. J. (2011). The influence of affective teacher-student relationships on students' school engagement and achievement: A meta-analytic approach. Review of Educational Research, 81(4), 493-529. https://doi.org/ 10.3102/0034654311421793

Samaila, K., Masood, M., \& Chau, K. T. (2021). Enhancing student's engagement and ICT skills through modified flipped classroom model. In 4th International Conference on Education (pp. 78-87).

Samuel, N., Onasanya, S. A., \& Yusuf, M. O. (2019). Engagement, learning styles and challenges of learning in the digital era among Nigerian secondary school students. International Journal of Education and Development Using Information and Communication Technology, 15(4), 35-43. 
Sarawagi, N. (2013). Flipping an introductory programming course: Yes you can! Journal of Computing Sciences in Colleges, 28(6), 186-188.

Schlairet, M. C., Green, R., \& Benton, M. J. (2014). The flipped classroom strategies for an undergraduate nursing course. Nurse Educator, 39(6), 321-325. https://doi.org/10.1097/NNE.00000000 00000096

Stone, B. B. (2012). Flip your classroom to increase active learning and student engagement. In 28th Annual Conference on Distance Teaching $\&$ Learning (pp. 1-5).

Sun, J. C. Y., Wu, Y. T., \& Lee, W. I. (2017). The effect of the flipped classroom approach to OpenCourseWare instruction on students self-regulation. British Journal of Educational Technology, 48(3), 713729. https://doi.org/10.1111/bjet.12444

Van Ryzin, M. J., \& Roseth, C. J. (2019). Effects of cooperative learning on peer relations, empathy, and bullying in middle school. Aggressive Behavior, 45(6), 643-651. https://doi.org/10.1002/ ab. 21858

Wen, A. S., Zaid, N. M., \& Harun, J. (2017). Enhancing students' ICT problem solving skills using flipped classroom model. In 2016 IEEE 8th International Conference on Engineering Education (pp. 187-192). https://doi.org/10.1109/ICEED.2016.7856069
Willingham, D. T., Hughes, E. M., \& Dobolyi, D. G. (2015). The scientific status of learning styles theories. Teaching of Psychology, 42(3), 266-271. https://doi.org/10.1177/0098628315589505

Xu, Z., \& Shi, Y. (2018). Application of constructivist theory in flipped classroom-Take college English teaching as a case study. Theory and Practice in Language Studies, 8(7), 880. https://doi.org/10.17507/tpls.0807.21

Zainuddin, Z., Habiburrahim, H., \& Hermawan, H. D. (2018). Designing a technology-enhanced flipped learning model using schoology LMS. In 2018 International Seminar on Intelligent Technology and Its Applications (pp. 245-250). https://doi.org/10.1109/ISITIA.2018.8710778

Zainuddin, Z., Haruna, H., Li, X., Zhang, Y., \& Chu, S. K. W. (2019). A systematic review of flipped classroom empirical evidence from different fields: what are the gaps and future trends? On the Horizon, 27(2), 72-86. https://doi.org/10.1108/OTH-09-2018-0027

Zakana, M. E., \& Esther, F. F. (2019). Effect of social networking sites on students' engagement and motivation in computer science in Bayelsa State, Nigeria. European Scientific Journal, 15(5), 132-145. https://doi.org/10.19044/esj.2019.v15n5p132 